\title{
"Ela Enxerga em Ti o Mundo": A Experiência da Maternidade pela Primeira Vez
}

\author{
Edinara Zanatta ${ }^{1}$ \\ Programa de Pós-Graduação em Psicologia da Universidade Federal de Santa Maria, \\ Santa Maria, RS, Brasil \\ Caroline Rubin Rossato Pereira \\ Departamento de Psicologia da Universidade Federal de Santa Maria, \\ Santa Maria, RS, Brasil
}

\begin{abstract}
Resumo
A chegada do primeiro filho configura-se como uma fase de muitas mudanças na vida da mulher. No âmbito psicológico, destacam-se os aspectos emocionais envolvidos com a gestação, o parto, o puerpério e a relação mãe-bebê. Este estudo buscou conhecer os sentimentos maternos acerca da gestação, do nascimento e da relação mãe-bebê em mulheres que vivenciaram a experiência da maternidade pela primeira vez. Participaram do estudo seis mães primíparas cujos bebês estavam na faixa etária de sete a doze meses e eram participantes do Programa da Criança de uma Unidade Básica de Saúde de uma cidade do interior do Rio Grande do Sul. A pesquisa teve caráter qualitativo, sendo utilizado como instrumento entrevistas semiestruturadas. Através da análise qualitativa de conteúdo foram identificadas as seguintes categorias temáticas: "Deu positivo: tô grávida" e Relação mãe-bebê: um processo de descobertas. Os resultados apontaram a presença de sentimentos como alegria, negação, surpresa e angústia frente à confirmação da gestação. O período gestacional foi marcado por instabilidade emocional e irritabilidade, além de sentimentos de insegurança em relação à maternidade. No que diz respeito à relação mãe-bebê, esta foi descrita pelas mães como sendo uma vivência gratificante e afetuosa. Além disso, houve um reconhecimento das dificuldades e deveres envolvidos no exercício da maternidade. Por fim, destaca-se a primeira experiência de maternidade como um momento intenso na vida da mulher, no qual é importante poder contar com o apoio de pessoas em quem ela confie e com quem se sinta segura.
\end{abstract}

Palavras-chave: Maternidade, relações mãe-filho, gravidez.

\section{"She Sees in You the World": The Experience of Motherhood for the First Time}

\begin{abstract}
The arrival of the first child is characterized as a period of many changes in women's lives. At a psychological level, it is highlighted the emotional aspects involved with pregnancy, childbirth, postpartum and mother-infant relationship. This study aimed to investigate maternal feelings about pregnancy, birth and the mother-infant relationship in women who experienced motherhood for the first time. Six first-time mothers whose babies were aged seven to twelve months and who were participants in the Children's Program at a Basic Health Unit of a city in the countryside of Rio Grande do Sul took part in this study. The data originated from semi-structured interviews were submitted to a qualitative analysis.
\end{abstract}

Endereço para correspondência: Av. Roraima 1000, Prédio 74B, Sala 3206A, CEP 97105-900, Santa Maria, RS, Brasil. E-mail: edi.zanatta@hotmail.com 
Two thematic categories - "Tested positive: I'm pregnant" and Mother-infant relationship: a process of discovery - were identified through content analysis. The results indicated the presence of feelings such as joy, denial, surprise and anguish at the confirmation of pregnancy. The gestational period was marked by emotional instability, irritability, besides feelings of insecurity about motherhood. With regard to the mother-child relationship, this was described by mothers as a rewarding and loving experience. Furthermore, there was recognition of the difficulties and duties involved with motherhood. Finally, the first experience of motherhood is highlighted as an intense moment in a woman's life, during which is important to count on the support of people she trusts and with whom she feels safe.

Keywords: Motherhood, mother-child relations, pregnancy.

\section{“Ella Ve en Ti el Mundo": La Experiencia de la Maternidad por Primera Vez}

\section{Resumen}

La llegada del primer hijo se configura como un momento de cambios en la vida de la mujer. En el ámbito psicológico, se destacan los aspectos emocionales que se involucran con la gestación, el parto, el puerperio y la relación madre-bebe. El presente estudio buscó conocer los sentimientos maternos sobre la gestación, el nacimiento y la relación madre-bebe en mujeres que vivenciaron la experiencia por primera vez. Participaron del estudio seis madres primíparas, cuyos bebes estaban en la edad de los siete a doce meses y participaban del Programa de Criança de uma Unidade Básica de Saúde, de una ciudad del interior de Rio Grande do Sul. La investigación tuvo un carácter cualitativo, con la utilización de entrevistas semiestructuradas y, con el análisis de contenido, se identificaron las siguientes categorías temáticas: "Positivo: estoy embarazada" y "La relación madre-bebe: un proceso de descubrimiento". Los resultados señalaron la presencia de sentimientos como alegría, negación, sorpresa y angustia frente la confirmación del embarazo. El período gestacional fue marcado por instabilidad emocional e irritabilidad, además de sentimientos de inseguridad sobre la maternidad. En la relación madre-bebe, esta fue descrita por las madres como una vivencia gratificante y afectuosa. Asimismo, hubo un reconocimiento de las dificultades y deberes que se involucran en el ejercicio de la maternidad. Por último, se enfatiza que la primera experiencia de la maternidad fue un momento intenso en sus vidas, en el cual es importante contar con el apoyo de las personas que confien y se sientan bien.

Palabras clave: Maternidad, relación madre-hijo, embarazo.

A vivência da maternidade constitui-se em uma experiência singular na vida da mulher, que envolve mudanças e adaptações (Lopes, Prochnow, \& Piccinini, 2010). No âmbito psicológico destacam-se os aspectos emocionais envolvidos com a gestação, parto e puerpério. Nesse sentido, além das alegrias associadas, o nascimento de um bebê pode caracterizar-se também como um momento de angústia, devido à reorganização psíquica pela qual os genitores precisam passar. A fase gravídeco-puerperal remete à vivência dos próprios genitores enquanto bebês, podendo reavivar lutos e conflitos inacabados (Oishi, 2014).
No caso das mães, os sentimentos vivenciados nesse período podem, também, estar associados à necessária redefinição dos papéis assumidos pela mulher até então (Dias \& Lopes, 2003). Durante a gestação, a mulher passa a se olhar e a ser vista de uma forma diferente, passando da condição de filha e mulher para a de mãe. Para que o papel de mãe possa ser apropriado pela mulher, supõe-se a necessidade de elaboração de um luto infantil, possibilitando à mulher acessar o lugar materno (Ferrari, Piccinini, \& Lopes, 2007; Soifer, 1980). Nesse processo, revive-se experiências anteriores, além de ter que se adaptar em seu relacionamento conjugal, 
sua carreira profissional e nas questões socioeconômicas (Maldonado, 1997; Piccinini, Gomes, Nardi, \& Lopes, 2008). Assim, esse é um momento que implica a possibilidade de grandes mudanças, envolvendo tanto ganhos como perdas (Maldonado, 1997), o que justificaria a presença de sentimentos ambivalentes em relação a essa vivência (Borsa \& Dias, 2007).

Ainda há que se considerar que a história e as experiências vividas pela mulher ao longo da sua vida podem influenciar no modo como ela irá desempenhar a maternidade do seu bebê. Nesse sentido, a relação da mulher com sua figura materna representa o principal modelo ao se tornar mãe. Desse modo, uma vivência satisfatória de cuidados, percebida como uma experiência gratificante, tende a gerar modelos positivos, enquanto experiências negativas associadas aos cuidados e à relação com a figura materna podem favorecer a uma experiência dolorosa e até infeliz da maternidade. Assim, esses modelos de identificação fazem parte do universo simbólico da mulher desde a sua infância e é com eles que a mulher irá se identificar ao desempenhar o papel de mãe (Felice, 2007).

Segundo Stern (1997), toda a preparação que a mulher realiza durante a gestação envolvendo expectativas, sonhos, medos e fantasias sobre como será o seu bebê, como ela desempenhará o papel de mãe e como o seu companheiro será como pai, além das transformações na sua vida com a chegada do bebê, são aspectos fundamentais para a construção da identidade materna. A este respeito, ao investigar o bebê imaginado pelas mães durante a gestação, Ferrari et al. (2007) identificaram que as mulheres reconheciam que os bebês que estavam gestando constituam-se em um novo sujeito, com características próprias, sentimentos e emoções, o que, consequentemente, desencadeava expectativas, medos e fantasias em relação ao seu próprio desempenho como mãe.

Assim, conhecer as expectativas maternas durante a gestação em relação ao seu bebê torna-se importante também para entender o lugar projetado pela mãe para o filho. Nesse sentido, Piccinini, Gomes, Moreira e Lopes (2004) apon- taram que com o avanço da gravidez a identificação de determinadas características do bebê, tais como sexo, nome, características psicológicas, interação mãe-bebê e saúde do bebê, serviram como estímulos para que se criassem mais expectativas e sentimentos em relação aos mesmos, favorecendo o vínculo mãe-bebê (Piccinini et al., 2004).

Dessa forma, há que se considerar que a gestação é um período caracterizado por significativas transformações envolvendo os vínculos afetivos e o mundo psíquico dos sujeitos. Além disso, há a influência dos fatores hormonais, culturais, ambientais, situações que podem desencadear estresse, e ainda, a influência da constituição da personalidade de cada sujeito. Sendo assim, a gestação é um momento muito intenso, que requer um esforço da mulher, em especial, para se adaptar e se reorganizar para o exercício da maternidade (Oishi, 2014).

De acordo com Winnicott (1987/1999), ao final da gravidez as mães psiquicamente saudáveis se preparam para se colocarem no estado de realizar a tarefa especial que terão de cumprir, voltando ao estado normal nas semanas e meses após o nascimento do bebê. Esse se configura como um estado de identificação com o bebê, que permite às mães se colocarem no lugar dos filhos, indo ao encontro de suas necessidades básicas, de uma forma que não pode ser imitada e nem ensinada. Esse estado especial de sensibilidade exacerbada é o que Winnicott (1958/2000) denominou de Preocupação Materna Primária. Nesse período, a mãe preocupa-se com o seu bebê e em atender e adaptar-se às suas necessidades, fornecendo as bases para o desenvolvimento da criança, excluindo de forma temporária e normal qualquer outro interesse que poderia vir a ter. Entretanto, não são todas as mães que conseguem contrair essa "doença normal", identificando-se com o seu bebê nessa fase inicial do desenvolvimento.

Em relação ao pós-parto, este se constitui em um período de adaptação física e emocional (Penna, Carinhanha, \& Rodrigues, 2006). Segundo os autores, além de voltar-se ao seu bebê, a mulher, agora mãe, precisa também lidar com 
o confronto entre as expectativas projetadas durante a gestação e a realidade do bebê com quem passa a interagir.

Autores como Spitz (1998) chamaram a atenção para a importância do contato inicial mãe-bebê para o desenvolvimento dessa relação. Assim, as ações realizadas pelo bebê que a mãe sente como agradáveis, são encorajadas e facilitadas por ela, influenciando seu desenvolvimento através das preferências maternas. Diante disso, pode-se dizer que "seus afetos, seu prazer, suas próprias ações, conscientes ou inconscientes, facilitam inúmeras e várias ações do filho" (Spitz, 1998, p. 125). No que tange às vivênicas maternas nos meses iniciais após o nascimento do bebê, Penna et al. (2006) investigaram mulheres puérperas atendidas em uma unidade básica de saúde do Rio de Janeiro e identificaram a presença de sentimentos de satisfação por parte das mulheres por serem mães de bebês saudáveis. Destacou-se que as mães não relataram maiores dificuldades ou desafios nesse momento. Nesse sentido, ficou evidente o investimento materno no bebê e o lugar que este passou a ocupar na vida das mães. A este respeito, as autoras salientam a necessidade da participação e colaboração dos demais membros da família a fim de dividirem as tarefas envolvidas neste período, não sobrecarregando a mulher em um momento em que ela precisa dedicar-se intensamente ao bebê.

Nesse sentido, desempenhar o papel materno considerando todas as mudanças implicadas no nascimento, em especial do primeiro filho, faz com que a mãe entre em uma nova e única forma de organização psíquica, chamada por Stern (1997) de "constelação da maternidade". Essa "constelação" atuará como uma organizadora dos processos psíquicos, sendo responsável pela "tendência à ação, sensibilidades, fantasias, medos e desejos" (Stern, 1997, p. 161). Assim, destacam-se quatro temas centrais referentes às novas atividades que a mãe irá desempenhar: vida e crescimento, relacionar-se primário, matriz de apoio e reorganização da identidade (Stern, 1997). O primeiro tema diz respeito às capacidades da mãe de manter a vida e o crescimento do bebê, envolvendo os aspectos físicos da criança.
O segundo refere-se à capacidade emocional da mãe de ligar-se ao seu bebê, de modo que propicie o desenvolvimento psíquico do mesmo. Este tema engloba a definição proposta por Winnicott (1958/2000) de Preocupação Materna Primária, considerando a capacidade da mãe de propiciar um ambiente suficientemente bom, sendo capaz de colocar-se no lugar do bebê sentindo as necessidades dele e suprindo-as. O terceiro tema refere-se à necessidade de uma rede de apoio que auxilie a mãe no processo de desenvolvimento do bebê, seja físico ou psíquico. Em relação ao quarto e último tema, este diz respeito à capacidade da mãe de se reorganizar no novo papel, passando de filha para mãe, de esposa para genitora, de profissional para mãe de família (Stern, 1997).

A partir do exposto, o presente estudo teve como objetivo compreender os sentimentos maternos acerca da gestação, do nascimento e da relação mãe-bebê em mulheres que vivenciavam a experiência da maternidade pela primeira vez.

\section{Método}

\section{Participantes}

Participaram desta pesquisa seis mães (M) que estavam vivenciando pela primeira vez a maternidade e cujos bebês encontravam-se na faixa etária de sete a doze meses, participantes do Programa da Criança de uma Unidade Básica de Saúde de uma cidade do interior do Rio Grande do Sul. Escolheu-se esse programa em específico por ser realizado no referido local um trabalho de atendimento com crianças na faixa etária entre zero a dois anos, cobrindo o período foco do estudo. No referido programa é realizado um trabalho de acompanhamento mensal das díades mãe-bebê. Além de constatar como está o desenvolvimento físico e motor das crianças, o Programa da Criança esclarece dúvidas e orienta as mães com relação ao desenvolvimento dos filhos, tanto nos aspectos físicos, realizado pela equipe de Enfermagem, como nos aspectos psíquicos, a cargo da equipe da Psicologia. Os dados relativos às características sociodemográficas das participantes podem ser visualizados na Tabela 1. 
Tabela 1

Características Sociodemográficas das Participantes

\begin{tabular}{lcccccc}
\hline & M1 & M2 & M3 & M4 & M5 & M6 \\
\hline Idade da mãe & 22 anos & 19 anos & 29 anos & 31 anos & 30 anos & 26 anos \\
Escolaridade & $\begin{array}{c}\text { Ens. Médio } \\
\text { incomp. }\end{array}$ & $\begin{array}{c}\text { Ens. Médio } \\
\text { incomp. }\end{array}$ & $\begin{array}{c}\text { Ens. Médio } \\
\text { completo }\end{array}$ & $\begin{array}{c}\text { Ens. Fund. } \\
\text { completo }\end{array}$ & $\begin{array}{c}\text { Ens. Médio } \\
\text { completo }\end{array}$ & $\begin{array}{c}\text { Ens. Médio } \\
\text { completo }\end{array}$ \\
Estado civil & casada & solteira & casada & casada & casada & casada \\
Idade do bebê & 9 meses & 7 meses & 8 meses & 12 meses & 9 meses & 7 meses \\
Sexo do bebê & masc. & fem. & masc. & masc. & fem. & fem. \\
\hline
\end{tabular}

\section{Delineamento e Procedimentos}

Este estudo teve caráter qualitativo e exploratório. Inicialmente, foi realizado o contato com a Secretaria Municipal de Saúde para a apresentação do projeto e solicitação da autorização institucional junto ao representante do Núcleo de Educação Permanente em Saúde. Posteriormente, o projeto foi submetido à apreciação pelo Comitê de Ética em Pesquisa (CEP) de uma universidade pública. Com a aprovação do projeto de pesquisa pelo CEP, a pesquisadora realizou o contato com a Unidade Básica de Saúde e o Programa da Criança.

As mães que participaram do estudo foram contatadas pela primeira autora deste estudo durante a consulta de puericultura no Programa da Criança desenvolvido na unidade, sendo agendadas as entrevistas conforme a disponibilidade das mesmas. Assim, quatro das seis participantes preferiram realizar a entrevista no mesmo dia, após a consulta. As demais optaram pela realização da entrevista no mês seguinte, quando retornariam para a consulta de rotina do bebê.

Considerando que este artigo é resultado de um trabalho de conclusão do curso, todas as entrevistas foram realizadas pela primeira autora do estudo, acadêmica do último semestre do curso de Psicologia, nas dependências da Unidade Básica de Saúde, em sala devidamente reservada e disponibiliza- da pela direção da mesma. Antes do início da entrevista, foi lido e assinado pelas participantes o Termo de Consentimento Livre e Esclarecido, momento em que ficaram cientes do objetivo da pesquisa e do compromisso com o sigilo por parte das pesquisadoras. As entrevistas foram gravadas em áudio para posterior transcrição. Duas codificadoras (a acadêmica de psicologia e sua orientadora) classificaram os relatos das participantes e eventuais discordâncias foram eliminadas através da discussão e do consenso. Os dados foram analisados através da análise de conteúdo qualitativa (Bardin 1977; Gomes, 2001), sendo que os aspectos que mais se fizeram presentes ou relevantes nas entrevistas foram agrupados, constituindo-se assim as categorias temáticas do presente estudo. Destaca-se ainda que o estudo está respaldado nas Diretrizes e Normas Regulamentadoras de Pesquisa envolvendo Seres Humanos (Resolução $\mathrm{N}^{\circ} 466$ do Conselho Nacional de Saúde, 2012) e na Resolução CFP N ${ }^{\circ}$ 016/2000 do Conselho Federal de Psicologia, tendo sido o projeto de pesquisa aprovado pelo Comitê de Ética de uma universidade pública.

\section{Instrumento}

Como instrumento de coleta de dados, foi utilizada uma entrevista semidirigida que abordou os seguintes tópicos: vivência e sentimentos 
despertados durante a gestação, experiência da maternidade e relação mãe-bebê. Para Gaskell (2002), esse tipo de entrevista fornece os dados básicos para a compreensão das relações que existem entre os atores sociais e a situação em que eles se encontram, sendo possível chegar a uma compreensão das crenças, atitudes, valores e motivações das pessoas em um contexto social específico.

\section{Resultados e Discussão}

A partir da análise de conteúdo qualitativa (Bardin, 1977; Gomes, 2001), duas categorias temáticas emergiram dos dados: (a) "Deu positivo: tô grávida" e (b) Relação mãe-bebê: um processo de descobertas. A seguir, serão apresentados os resultados para cada uma dessas categorias, ilustrando-os com as falas das participantes.

\section{"Deu Positivo: Tô Grávida”}

Esta categoria refere-se às expectativas e sentimentos vivenciados pelas mães primíparas durante a gestação, marco de uma nova fase em suas vidas. Os relatos das mães foram divididos em três subcategorias denominadas: (a) A notícia da gravidez, (b) Os sentimentos vivenciados durante a gestação e (c) Expectativas em relação à maternidade.

A Notícia da Gravidez. Esta primeira subcategoria destaca a reação da mãe e os sentimentos suscitados pela notícia da gravidez. Descobrir que se está à espera de um bebê é um evento que marca profundas mudanças na vida de uma mulher (Klaus, Kennell, \& Klaus, 2000; Marin, Gomes, Lopes, \& Piccinini, 2011; Szejer \& Stewart, 1997). A notícia da confirmação da gestação pode ser vivenciada de diferentes modos pelas mulheres. Entre eles, identificou-se o sentimento de alegria, referido por uma das participantes que estava tentando engravidar há algum tempo: "Deu positivo, eu quase morri de alegria" (M3). Para outras mães, esse momento foi marcado pela presença de sentimentos angustiantes: " $A$ i, Deus o livre. Eu não planejei, né" (M2); "Parece que não caía a ficha, sabe" (M4). Entretanto, passado o impacto da notícia, destaca-se o cuidado e o investimen- to desta mãe em poder aproveitar esse momento, voltando-se mais para si mesma e para o bebê, do que para outras atividades que até então eram prioridade, a exemplo do trabalho: " $A i$ eu comecei a me estressar no trabalho, dai eu fiquei em casa, só curtindo a gravidez, curtindo a barriga" (M4).

Além disso, outra característica destacada foi a presença de sentimentos ambivalentes frente às manifestações da gestação e à posterior confirmação da mesma através de exames:

Todo sintoma que eu sentia achava que era coisa da minha cabeça porque eu queria engravidar. Ai se eu ficava tonta eu dizia: "Ah, não é nada". Daí eu olhava no espelho assim em casa e: "Ai, bem que podia ser, mas não é nada". Ai fiz um exame de farmácia de manhã e deu positivo, mas eu achei que tinha dado errado. Comprei outro de tarde. Fiz o exame de tarde, deu positivo. No outro dia, eu fui lá no laboratório tal, fiz o exame, ai deu positivo. Dai eu fiquei feliz, né. Já tava com seis meses e meio quando eu descobri. (M5)

Nota-se, a partir dessa fala, que a presença dos sinais da gestação foram negados pela mãe até a metade do segundo trimestre. O temor de mais uma vez se decepcionar com o resultado negativo pode ter contribuído para adiar a confirmação da gestação, o que, segundo ela, influenciou em suas atitudes posteriormente: "Não tinha espaço pra ficar triste. Eu tinha que fazer o chá, tinha que preparar a casa, tinha que arrumar o berço. Ela já tava nascendo" (M5).

De acordo com Maldonado (1997), a presença desses sentimentos pode surgir ao longo dos três trimestres de gestação e também após o nascimento do bebê. A gravidez exige grandes adaptações e mudanças, o que consequentemente envolve ganhos e perdas, podendo justificar a presença de sentimentos ambivalentes, mesmo após a confirmação com exame clínico (Silva, Souza, \& Scorsolini-Comin, 2013).

Ainda, apesar de algumas mães terem planejado a gravidez, houve uma reação de surpresa diante da confirmação. Nesse caso, parece haver um embate entre o desejo de querer engravidar e a concretização da notícia, o que pode levar a 
pensar na existência de sentimentos contraditórios frente ao acontecimento:

Eu não imaginava que eu ia engravidar tão rápido porque eu tomava remédio há 11 anos e eu engravidei em dois meses, mais ou menos. . . . Eu senti ele com cinco meses mais ou menos. Ai é que foi caindo a ficha, sabe, quando coloca as roupas não serve mais. Coloca a calça de elástico e ela dobra pra baixo. (M4)

Além disso, para uma das mães, a notícia da gestação constituiu-se em um período de intensa angústia. Frente a uma gravidez não planejada, ela referiu sentimentos de insegurança devido à inexperiência e à falta de suporte familiar, em especial da figura materna: "É porque eu tinha 18 anos. Eu pensava que ia ser difícil, até porque eu não tinha experiência nenhuma. A minha mãe que pudesse ir comigo, não tá nem al" (M2).

$\mathrm{O}$ contexto das relações familiares da gestante apresentava-se fragilizado, tornando-se um obstáculo a mais nesse momento, no qual se nota um sentimento de tristeza em não poder contar com a figura materna. De acordo com Stern (1997), a presença da matriz de apoio à nova mãe no decorrer da gestação e do desenvolvimento do bebê é fundamental para auxiliá-la nos momentos de dúvida. Além disso, oferece-se como figura com quem ela pode se identificar ao desempenhar os cuidados de seu bebê.

Os Sentimentos Vivenciados Durante a Gestação. Nesta segunda subcategoria, serão apresentados os sentimentos vivenciados pelas mães durante a gestação, sendo esse um momento que reaviva muitas emoções na mulher. Assim, sentir-se mais emotiva, chorar com mais facilidade, estar mais sensível e suscetível às alterações de humor foram aspectos mencionados pelas participantes ao referirem as mudanças percebidas ao longo da gestação: "No começo até não era tanto, mas no final, eu chorava por nada" (M4); "Eu fiquei meio emotiva. Uma hora tava feliz, outra hora triste" (M2); "A gente fica bem mais sensivel, mais frágil" (M3); "Eu chorava mais fácil" (M1). A instabilidade emocional vivenciada pelas mães pode estar associada às várias mudanças e ajustes necessários nesse período, entre eles podem-se citar os aspectos emocionais e físicos relacionados às transformações do corpo, em decorrência do desenvolvimento do bebê (Klaus et al., 2000).

Perceber o desenvolvimento do filho através do movimento fetal também foi referido como uma experiência alegre e emocionante: "E ela mexia bastante também na minha barriga. Ah, era muito boa [a sensação]. Tinha épocas que eu até chorava" (M6). Perceber os movimentos do bebê sinaliza um momento muito importante da gestação, pois permite que o bebê se torne mais real e personificado, aumentando as expectativas em relação a ele. O modo como as mães percebem esses movimentos possibilita irem atribuindo características específicas ao seu bebê, bem como interpretar determinados movimentos como sendo algo que o bebê desejou expressar (Piccinini et al., 2004). Assim, a gestação refere-se a um momento em que é necessário criar um lugar para esse bebê. Lugar este que é possibilitado muitas vezes através das expectativas criadas sobre ele, influenciando também uma mudança de papel da própria mulher, que além de filha, passará a ser mãe. Todas essas mudanças e ajustes podem contribuir para que a mulher experiencie a gestação como um período de maior sensibilidade emocional (Coldebella, 2006; Maldonado, 1997; Piccinini et al., 2004).

Além da maior sensibilidade, foi referida também a presença de sentimentos de irritabilidade: "Ah, eu me irritava toda hora, mas ele [marido] entendia. Ele sabia que era por causa disso [gravidez]. Eu não podia escutar a voz do pai dele dentro de casa. Qualquer coisinha pra mim, ai, eu não podia" (M3).

O sentimento de irritabilidade com o marido durante a gestação vai ao encontro da literatura que destaca uma maior probabilidade de sua ocorrência no primeiro trimestre da gravidez (Piccinini et al., 2008). Esse sentimento pode estar relacionado ao conjunto de adaptações, sejam elas pessoais ou interpessoais, às quais a gestante precisa responder (Maldonado, 1997). A irritação pode se configurar como a maneira pela qual a mulher consegue externalizar as dificuldades encontradas nesse processo, direcionando esse comportamento ao companheiro, visto ser ele, na maioria das vezes, a pessoa mais próxima 
a ela (Piccinini et al., 2008). Além disso, pode-se cogitar que essa reação estivesse expressando dificuldades relativas ao relacionamento conjugal que não foram mencionadas pela participante na entrevista.

Ainda, a preocupação da mãe em estar prejudicando o bebê a partir dos seus sentimentos, também foi mencionada: "Eu pensava muito, todo mundo diz: 'Procura te controlar no que tu sente, porque tudo o que tu sente passa pra criança" (M5). Percebe-se haver um entendimento de que a mãe e o bebê estariam unidos não somente do ponto de vista biológico, mas psicologicamente também. Nessa perspectiva, a mãe emprestaria ao filho o seu corpo e o seu psiquismo para o desenvolvimento do mesmo e assim contribui para os resultados bons ou ruins desse enlace (Marin et al., 2011).

Expectativas em Relação à Maternidade. Nesta terceira subcategoria, que se refere às expectativas em relação à maternidade, ficou evidente, nas verbalizações das mães, o sentimento de insegurança em como desempenhar o papel materno: "Eu pensava que ia ser dificil. Então, eu dizia: 'Deus eu não sei nada'. Eu não sabia nada. Era o meu maior temor, não saber cuidar da minha filha" (M2). De acordo com Maldonado (1997), apesar de cada gestação ter um significado especial e novo para a mãe, considerando-se as mães primíparas, a inexperiência frente à maternidade pode ser considerada um fator a mais contribuindo para a insegurança materna, especialmente nos primeiros meses após o nascimento do bebê, período importante de adaptação mãe-bebê.

As expectativas das mães em relação à maternidade podem apresentar repercussões tanto positivas como negativas para a relação mãe-bebê e para o desenvolvimento psíquico da criança (Piccinini et al., 2004). Através da fala da seguinte mãe percebeu-se o investimento e o envolvimento com o bebê como foco de investimento emocional da mãe desde a gestação: " $T i$ nha muita expectativa. É o primeiro filho, então, tu quer que seja o melhor, o mais lindo. A prioridade era ele. A prioridade é o meu filho" (M3).

Além disso, imaginar como o bebê vai ser, com quem ele será parecido, como será o seu temperamento, tudo isso gera expectativas nas mães, como podem ser visualizadas nas seguintes falas: "As coisas vão acontecendo e você vai vivendo. Eu sempre pedia muito que ele fosse calminho, que fosse uma criança calma, tranquila" (M4); "Só o que eu pensava era: "Como é que vai ser a carinha dele? Como é que ele vai ser?"” (M1); "Ficava pensando isso é coisa de guri, isso é coisa de guria. Mas no fundo, no fundo, eu sempre pensava que ia ser uma menina" (M6).

A partir do exposto, é possível reconhecer que o investimento presente no discurso das mães conota o interesse em construir um vínculo, identificando-se com esse bebê e tornando-o mais real (Coldebella, 2006; Piccinini et al., 2004). Mesmo antes da identificação do sexo do bebê, os progenitores já apresentam uma ideia prévia sobre suas características (Klaus \& Kennel, 1992; Piccinini et al., 2004). Conhecer o sexo do bebê durante a gestação também se mostra importante na medida em que possibilita que ele exista de outra forma, agora com uma identidade mais delineada, sendo possível nomeá-lo (Coldebella, 2006).

Além disso, os preparativos para a chegada do novo integrante da família foram relatados pelas mães: "Eu queria a parede [do quarto] azul, eu queria adesivo na parede" (M3);

A sensação do nenê mexendo, tu organizando as roupas, o roupeiro, as roupinhas, o que falta, o que que não falta. Ai tu organiza o chá de bebê, aquela função, tem isso, tem aquilo, falta aquele outro, aquele outro. Ai vem vindo mais pro final, de montar o berço, essas coisas. É bom. É muito bom mesmo. (M4) Assim, a identificação com o bebê e os investimentos em criar um lugar que é especialmente pensado para ele, favorecem que essa criança exista e se torne cada vez mais real, ocupando o seu lugar na família como um sujeito separado da mãe, como um ser independente (Coldebella, 2006; Szejer \& Stewart, 1997). Dessa forma, percebeu-se a importância das expectativas apresentadas pelas mães participantes do estudo durante a gestação, que possibilitaram pensar, desejar e organizar o lugar que esse filho viria a ocupar em suas vidas. 


\section{Relação Mãe-Bebê: Um Processo de Descobertas}

Nesta segunda categoria, serão destacadas as impressões maternas acerca do nascimento do bebê e sobre a experiência da maternidade após esse momento. Para isso, os resultados serão apresentados em quatro subcategorias: (a) A chegada do bebê, (b) Ser mãe é..., (c) A relação mãe-bebê e (d) $\mathrm{O}$ momento da amamentação para o par mãe-bebê.

A Chegada do Bebê. Esta subcategoria destaca o momento do nascimento do bebê e a reação da mãe frente a esse acontecimento. Segundo Marin, Donelli, Lopes e Piccinini (2009), "o nascimento do bebê, especialmente quando é o primeiro, representa um marco na vida de todos os envolvidos" (p. 58). O parto inaugura o momento em que efetivamente a mãe entra em contato com o seu filho, o que por si só gera muitas expectativas. Aliada a isso, acrescenta-se a influência cultural, que o associa à dor (Cunha, Santos, \& Gonçalves, 2012), sendo este um aspecto desencadeador de medo: "Quando a criança tá na barriga, a gente não sabe muito como que é. As pessoas em volta de mim sempre me apavoravam. Eu sempre olhava os vídeos [de partos] $e$ fiquei apavorada" (M2).

Após o nascimento do bebê, essa dor foi referida pelas mães a partir de outra dimensão, na qual a emoção por estar com o filho tornou-se mais significativa do que o desconforto do momento do nascimento: "É uma dorzinha que eu já nem lembro mais. Que nem a minha mãe dizia, é uma dor falsa, porque depois tu esquece" (M5); "É uma emoção que você não tem como dizer o que você sente. A gente não sabe se ri, não sabe se chora" (M4); "Quando eu vi a carinha dele aqui, eu já me emocionei" (M1).

Dessa forma, o parto marca o momento em que um novo sentindo é dado à experiência da maternidade (Borsa \& Dias, 2007). Introduz, em um curto espaço de tempo, significativas mudanças na vida da mulher e de sua família. Diante disso, o nascimento do bebê define a passagem de um estado para outro, no qual a mulher torna-se mãe, cuja principal característica diz respeito à irreversibilidade (Maldonado, 1997; Marin et al., 2009).
Do ponto de vista emocional, o nascimento representa um processo de separação entre a mãe e o bebê. Esse processo pode ser vivenciado pela mulher como perda de uma parte de si, caso não tenha sido elaborada a diferenciação entre mãe e filho desde a gestação (Maldonado, 1997; Marin et al., 2009). Refere-se a um momento em que a mulher pode se encontrar fragilizada, necessitando da compreensão e ajuda tanto dos profissionais de saúde quanto dos familiares. Neste contexto, o contato mãe-bebê logo após o nascimento é fundamental, pois é um momento sensível e propício para o desenvolvimento do apego. Assim, deixar a mãe tocar no seu bebê e que eles se sintam acariciados, acalmando-se, faz com que a mãe se sinta mais segura e continue investindo no bebê (Rosa et al., 2010).

Ser Mãe É... Esta subcategoria discorre acerca das impressões das mães sobre a experiência da maternidade. As participantes identificaram a maternidade como uma vivência intensa, pautada pelo amor e afeto por seus bebês: " $A h$, eu acho que é maravilhoso" (M2); "A coisa melhor do mundo. É amor pra toda a vida" (M3); "Ser mãe é a melhor coisa que existe" (M6).

O modo como as participantes expressaram o sentimento de ser mãe parece ser o reflexo de todo o investimento afetivo despendido aos seus bebês de forma espontânea, assim como do comportamento deles dirigido a elas, ficando clara a reciprocidade existente na relação da díade: "Ele já se acorda, olha pra mim, e dá a risadona dele" (M1); "[Ser mãe] é a retribuição de quando tá brincando, o sorriso que ela te dá" (M5). A esse respeito, segundo Borsa e Dias (2007), o vínculo construído na relação mãe-bebê extrapola em muito o interesse em alimentar, trocar ou tomar conta do bebê. Refere-se a cuidar e colocar-se no lugar do bebê, perceber e responder às suas necessidades físicas e emocionais.

Nesse sentido, destaca-se a importância da maternidade na vida dessas mulheres na medida em que elas indicaram o "colorido" que o bebê conferiu a suas vidas: "Antes ficava só eu trancada dentro de casa sozinha. Eu quase entrei em depressão. Depois que veio ele, fica eu e ele, a gente faz bagunça, a gente se diverte" (M1). Nesse caso, além da satisfação expressa pela 
participante, ressalta-se o cuidado de diferenciar o lugar ocupado por essa criança e o lugar da mãe, não conferindo ao bebê a responsabilidade de preencher um espaço demasiadamente penoso e difícil na vida da mãe, o que pode vir a prejudicar ambos.

Além disso, é interessante pontuar a capacidade das mães de verbalizarem não somente os aspectos positivos da maternidade, como também as dificuldades envolvidas: "Dá trabalho, mas é muito bom" (M1); "Em primeiro lugar é bastante responsabilidade" (M2); "Ele é meu filho, mas ele cansa. Eu vou passar o dia intero com ele e eu sou sozinha em casa, faço tudo" (M3).

Dessa forma, apesar de estarem satisfeitas no seu papel de mães, fica claro o reconhecimento das dificuldades e deveres envolvidos no exercício dessa função. Pode-se perceber que elas reconhecem não somente o aspecto idealizado da maternidade, mas também sua dimensão real, o que implica nos desafios diários desse papel, que envolve um novo ser frágil e dependente de seus cuidados (Strapasson \& Nedel, 2010).

A Relação Mãe-Bebê. Nesta subcategoria, a ênfase está centrada na relação estabelecida entre a mãe e o bebê, destacada a partir das falas maternas. Nesse contexto, é importante salientar que a maternidade constitui-se em um processo que se inicia em etapas anteriores à gestação e se prolonga após o nascimento do bebê, através da interação da dupla (Cunha et al., 2012; Piccinini et al., 2004).

Destaca-se, a partir do relato das mães, o sentimento de satisfação para com a relação estabelecida com seus bebês, perceptível através da comunicação e da brincadeira: "Pra mim é perfeita [relação mãe-bebê]. Eu entendo ele, me representa que ele me entende" (M4); "Quando a gente vai brincar e eu vejo que ele aprendeu bastante coisa" (M1); "Ontem eu fiquei numa alegria que ele comeu laranja comigo pela primeira vez, sabe, e ele pedia mais" (M3).

Além disso, algumas mães destacaram a importância do sorriso do bebê como sinal de resposta a elas e da ligação afetiva estabelecida entre os dois: "Quando ela dá aquele sorrisão dela, aquela risadona dela é a coisa mais linda" (M6); "E ela sorri, assim, é um sorriso tão bonito e tão sincero dela, que não tem maldade. Ela tá rindo ali da situação, da brincadeira. Eé muito bom" (M5).

De acordo com Maldonado (1997), passado o período de adaptação inicial do bebê ao mundo externo, na medida em que organiza o seu ritmo próprio, o bebê torna-se mais calmo e vai se estabelecendo uma comunicação entre o par mãe-bebê. Pode ser através do olhar e do sorriso que a criança descobre o mundo, despertando na mãe um sentimento de gratificação pela consolidação de uma verdadeira relação de troca.

Ressalta-se também na interação da díade, a possibilidade de a mãe reconhecer as necessidades do bebê. Entretanto, isso é um exercício, uma aprendizagem diária, especialmente quando se considera a experiência da maternidade pela primeira vez:

[No início] Não sabia nada. Eu via que ela tava chorando, dai eu via se não era dor no ouvido, ai passava a mão. Se não era dor de barriga. Daí eu fui olhando, aí comecei a pegar os choros. Agora hoje eu já sei. Mas é tudo passar pela experiência pra aprender. (M2)

De acordo com Borsa e Dias (2007), as dificuldades iniciais do reconhecimento do choro e das necessidades do bebê devem-se ao fato de que, nas primeiras semanas, a díade se conhece muito pouco, não havendo o estabelecimento de um padrão de comunicação entre mãe e filho, podendo haver dificuldades na distinção dos sinais do bebê. Entretanto, na medida em que este par passa a interagir, esse reconhecimento tende a se tornar mais especializado, através da empatia e da disponibilidade materna, tornando-se, inclusive, uma fase de descobertas: "Cada vez que ele aprende mais coisas a gente fica mais emocionado" (M1); "Tudo que eu falo ela entende" (M2); "O olhar que ela dá que tu sente, assim, que ela enxerga em ti o mundo. Porque tudo o que tu faz é o que ela tá aprendendo" (M5);

Cada dia ele faz uma coisa diferente, às vezes apronta, às vezes não. Agora mesmo ele tá tentando ficar sozinho sem se segura nas coisas. Ele levanta e fica sem se agarrar em nada, quando vê cai pro lado, aí dá risada. (M4) 
Nesse sentido, destaca-se o fato de a mãe ser quem passa a maior parte do tempo com o bebê, o que favorece o fortalecimento dos laços afetivos e a percepção do desenvolvimento e crescimento do mesmo. Isso pode ser destacado através de sentimentos de contentamento ao perceberem as novas aquisições e habilidades do bebê: "Todo o dia a gente passa junto. Agora que ela tá grandinha, então ela já brinca. E ela dá risada. Então, quando a gente brinca, que ela olha, que ela fica prestando atenção" (M5);

Eu tô sempre com ele. Eu faço o que eu tenho que fazer enquanto ele tá dormindo, porque o resto do tempo tudo eu brinco com ele. Quando a gente vai brincar e eu vejo que ele aprendeu bastante coisa. Ele brinca sozinho, ele joga bola sozinho, ele brinca de carrinho. Depois eu vejo assim: "ele cresceu". (M1)

Diante disso, a percepção das mães acerca do desenvolvimento dos seus filhos está de acordo com estudos sobre as mudanças que ocorrem ao longo do primeiro ano de vida do bebê, englobando desde o crescimento físico até o emocional, com destaque para as aquisições da linguagem, locomoção e exploração do ambiente e dos objetos. Nesse sentido, o papel materno está associado à capacidade de possibilitar ao filho a liberdade para se afastar dela e explorar o ambiente, bem como estar à disposição, tanto física quanto emocionalmente, no momento do seu retorno. A maneira como a mãe se coloca à disposição para atender às necessidades da criança nesse momento pode repercutir significativamente no seu desenvolvimento emocional (Lopes et al., 2007).

Um aspecto relevante no que diz respeito às mães no período pós-parto refere-se ao fato de que todas as participantes do estudo decidiram não voltar para seus empregos após o período de licença maternidade, priorizando acompanhar o dia a dia da criança, ocupando-se prioritariamente com o papel de mãe, esposa e dona de casa: "Eu sai do meu trabalho pra ficar com ela. Então, eu vou ficar com ela. Eu vou acompanhar o crescimento dela" (M5); "Eu abri mão do meu serviço pra ficar com ela. Mas é muito bom. Não me arrependo em nenhum momento" (M6).
Considerando-se que o estudo foi realizado junto a uma população de baixa renda, para a qual se faz importante a inserção das mulheres no mercado de trabalho a fim de colaborar com o sustento da família, pode-se perceber a importância assumida pela maternidade na vida destas mulheres neste período. A esse respeito, pode-se ainda cogitar que tenham influenciado tal decisão fatores como a baixa realização pessoal e baixa renumeração financeira, sendo que as participantes estavam vinculadas a trabalhos não especializados. Desse modo, torna-se fundamental considerar os diversos atravessamentos, sejam eles, pessoais, sociais ou culturais, presentes nessa população ao vivenciar a maternidade.

O Momento da Amamentação para o Par Mãe-Bebê. Esta última subcategoria refere-se às impressões maternas sobre a amamentação. Segundo Maldonado (1997), essa não deve ser considerada como um processo orgânico exclusivo, mas sim uma forma de comunicação mãe-bebê sentida através do contato pele a pele, da troca de olhares e do carinho transmitido nessas ações, podendo ocorrer tanto pela amamentação no peito como na mamadeira. Deve-se pontuar que, no momento da realização das entrevistas, todas as participantes do estudo estavam amamentando seus bebês no peito, sendo conotados sentimentos afetuosos a essa experiência: "Ter aquele carinho com ela, a retribuição do afeto, de tá juntinho. Porque o amamentar também aproxima bastante. Que é aquele momento que eu sei que é eu e ela" (M5); "É bom porque ao mesmo tempo que eu tô amamentando ele, a gente tá se redescobrindo. Que dai ele faz carinho e eu canto pra ele dormir" (M1); "Pra mim, é mágico. Ela fica me olhando. Ela dá risada. Daí ela resmunga e conversa comigo, eu converso com ela. Eu acho que é o momento que ela tá mais conectada comigo" (M2); “Às vezes, ela fica no peito, olha, dá aquele sorriso dela, solta, quer conversar, faz as enroladas dela, depois volta de novo pro peito. É muito bom. É único. É um momento que não tem explicação. Bom mesmo" (M6).

Nesse sentido, destaca-se o papel da amamentação para o estabelecimento do vínculo entre a mãe e o bebê, colocando-os em uma mesma sintonia. Assim, esse momento é percebido 
como prazeroso para ambos, com demonstração de afeto e carinho, além de ser um momento lúdico. De acordo com Winnicott (1987/1999), a amamentação pode significar um momento muito intenso tendo em vista a experiência de união e intimidade proporcionada pelo contato do seio materno com a boca do bebê, gerando, satisfação, prazer e sensação de completude para a dupla. No entanto, segundo Costa e Locatelli (2008), esse ato só pode ser vivenciado plenamente quando for desejado pela mulher, ou seja, quando ela possui o desejo real e a disponibilidade interna para amamentar.

Alguma dificuldade também foi relatada por uma mãe em relação ao momento inicial da amamentação. Contudo, esse aspecto esteve menos presente nas falas maternas frente à intensidade emocional que a experiência da amamentação proporcionou para a díade:

No começo, era dificil, porque, como era cesárea, o mamá não vem logo. Aí eu sentia muita dor, ele chorava, eu chorava junto de pena dele chorar de fome e da dor que eu sentia. Mas eu não desisti, eu tentava, até que veio normal. (M4)

Percebeu-se ainda, a sensibilidade materna às necessidades e ao ritmo do bebê para a amamentação. Uma mãe referiu tristeza ao perceber que ela e seu bebê não foram respeitados em sua adaptação para a amamentação. Diante disso, chama a atenção a identificação materna com o bebê, com quem a mãe desejaria compartilhar o protagonismo desse primeiro contato. Com isso, sinaliza a importância desse momento e o quanto ele ultrapassa os aspectos nutritivos:

Todo mundo diz que a hora da amamentação é a hora que você constrói o laço. Eu não pude ter. Como foi cesárea eu tava meio dormente em cima da cama. Pois dai ele não conseguia pegar e a enfermeira veio e empurro a cabecinha dele, pobrezinho. Me deu uma pena. Dai ele chorou. Daí foi que ele achou o peito, pegou o peito. Ele não queria largar mais. Eu queria que ela tivesse feito com carinho. Eu fiquei tão sentida porque eu queria que fosse diferente, que eu colocasse na boquinha dele. (M3) Embora o ato de amamentar não seja ga- rantia para o desenvolvimento de um vínculo adequado mãe-bebê, este pode se configurar em uma oportunidade rica para a constituição desse laço (Costa \& Locatelli, 2008). Isso pôde ser percebido através do desejo materno de que esse momento fosse pautado no carinho e na troca afetiva, salientando o significado que esse evento possui para a constituição da maternidade e a interação mãe-bebê.

\section{Considerações Finais}

Como se pôde perceber através do presente estudo, a maternidade inaugura uma fase de muitas mudanças na vida da mulher, repleta de sentimentos intensos. Nesse sentido, o momento da confirmação da gestação foi acompanhado por diversos sentimentos, entre eles: ambivalência, angústia, negação, surpresa e alegria. Destaca-se que a presença de sentimentos como a angústia e a negação não constituem-se como definidores para a relação mãe-bebê que se estabelece. No caso das mães do presente estudo, com o decorrer do desenvolvimento da gestação, percebeu-se o investimento na mesma e no bebê.

As expectativas em relação ao bebê vivenciadas pelas participantes durante a gestação parecem demonstrar como a relação mãe-bebê vai se fortalecendo ao longo deste período. Percebeu-se o investimento das mães no bebê que estavam gestando. E essas expectativas maternas possibilitaram que o bebê se tornasse cada vez mais real, projetando um lugar para ele na família. Assim, ressalta-se a importância das expectativas que contribuem para o investimento no bebê, para o desenvolvimento do vínculo entre a díade e como parte do processo constitutivo da maternidade.

Em relação aos sentimentos durante a gestação, destacou-se a instabilidade emocional verbalizada pelas mães, que referiam estarem mais sensíveis e chorar com mais freqüência nesse período. Além disso, a irritabilidade dirigida ao companheiro também foi mencionada, talvez sendo esse o meio encontrado para manifestar o seu sentimento frente a todas as mudanças e adaptações que a gestação exige da mulher, e direcionado a esse por ele ser a pessoa mais próxima naquele momento. 
O nascimento do bebê marca um momento repleto de sentimentos, expectativas, medo e ansiedades. Contudo, a emoção do contato da mãe com o bebê parece fazer com que as dificuldades inerentes ao processo de nascimento sejam pouco significativas frente ao que representou estar com o filho. No caso do presente estudo, essas dificuldades não pareceram prejudicar a relação. Pode-se cogitar que o desfecho feliz apresentado pelas participantes relaciona-se ao fato de que todas tinham uma figura de apoio, seja o marido, o pai ou a avó materna, com quem puderam contar nesse momento. Assim ressalta-se a importância de poder contar com pessoas em quem a mãe confie e se sinta segura nesse momento especial (Lopes et al., 2010; Stern, 1997).

Dessa forma, a maternidade foi apresentada pelas mães como uma experiência gratificante, representando um momento único em suas vidas. Contudo, houve também um reconhecimento por parte das mães de que este momento apresenta suas dificuldades e é trabalhoso, demonstrando um caráter não idealizado da maternidade.

Ainda, a amamentação foi apontada pelas mães como um momento em que mãe e filho estão se conhecendo e que favorece sua aproximação. Além disso, também foi evidenciada a redefinição dos papéis assumidos pelas mulheres do estudo nessa nova fase de suas vidas, destacando-se que todas as participantes optaram por não retornar ao mercado de trabalho após o período de licença maternidade.

Nesse sentido, esse estudo possibilitou pensar na maternidade como um processo complexo, sendo que a confirmação da gestação sinaliza o início de um novo ciclo na vida da mulher, podendo haver reações intensas ao longo deste caminho. Assim, por mais que tornar-se mãe seja um desejo dela e uma vivência prazerosa, pode-se pensar também na fragilização da mulher diante desse evento, necessitando para tanto cuidado e apoio das pessoas próximas a ela, incluindo tanto profissionais quanto familiares e amigos.

Por fim, destaca-se que, conforme o relato das participantes do presente estudo, a primeira experiência da maternidade foi apresentada como sendo uma vivência gratificante, intensa e desejada pelas mães. Contudo, todas as mães que se dispuseram a participar do estudo frequentavam um serviço de saúde pública materno infantil, no qual realizavam o acompanhamento do desenvolvimento dos bebês e tiravam dúvidas referentes a maternidade. Acredita-se que esse espaço possa ter contribuído para uma experiência mais satisfatória em relação à maternidade. Assim, essa percepção pode não representar uma grande parcela das mães, visto que o estudo englobou somente mulheres adultas, que possuíam um emprego antes do nascimento do filho e, com exceção de uma, todas viviam em um relacionamento estável com o pai do bebê. Dessa forma, cogita-se que realidades maternas diversas não tenham sido acessadas através desse estudo. Destaca-se, então, a importância de que novas pesquisas abordando esse tema poderão ser desenvolvidas a fim de melhor explicitar as diversas vivências do processo de tornar-se mãe.

\section{Referências}

Bardin, L. (1977). Análise de conteúdo. Lisboa, Portugal: Edições 70.

Borsa, J. C., \& Dias, A. C. G. (2007). Considerações acerca da relação mãe-bebê da gestação ao puerpério. Revista Contemporânea: Psicanálise e Transdisciplinariedade, 2, 310-321.

Coldebella, N. (2006). Expectativas e sentimentos acerca do bebê em gestantes primíparas e secundiparas (Dissertação de mestrado, Instituto de Psicologia, Universidade Federal do Rio Grande do Sul, Porto Alegre, RS, Brasil).

Conselho Federal de Psicologia. (2000, 22 dez.). Resolução CFP No 016/2000, 20 de dezembro de 2000. Diário Oficialda União, 246, Seção 1,p. 91.

Conselho Nacional de Saúde. (2012). Resolução $N^{\circ}$ 466, de 12 de dezembro de 2012. Recuperado em http://conselho.saude.gov.br/resolucoes/2012/Reso466.pdf

Costa, P. J. D., \& Locatelli, B. M. (2008). O processo de amamentação e suas implicações para a mãe e seu bebê. Mental, 6(10), 85-102.

Cunha, A. C., Santos, C., \& Gonçalves, R. M. (2012). Concepções sobre maternidade, parto e amamentação em grupo de gestantes. Arquivos Brasileiros de Psicologia, 64(1), 139-155. 
Dias, A. C., \& Lopes, R. S. (2003). Representações de maternidade de mães jovens e suas mães [Número especial]. Psicologia em Estudo, 8, 63-73. doi:10.1590/S1413-73722003000300009

Felice,E.M.(2007). Transformaçãoe "cura" através da experiência de ser mãe. Psychê, 11(21), 145-159.

Ferrari, A. G., Piccinini, C. A., \& Lopes, R. C. (2007). O bebê imaginado na gestação: Aspectos teóricos e empíricos. Psicologia em Estudo, 12(2), $305-$ 313. doi:10.1590/S1413-73722007000200011

Gaskell, G. (2002). Entrevistas individuais e grupais. In M. Bauer \& G. Gaskell (Eds.), Pesquisa qualitativa com texto, imagem e som (pp. 64-89). Petrópolis, RJ: Vozes.

Gomes, R. (2001). A análise de dados em pesquisa qualitativa. In M. C. S. Minayo (Ed.), Pesquisa social: Teoria, método e criatividade (pp. 6780). Petrópolis, RJ: Vozes.

Klaus, M. H., \& Kennel, J. H. (1992). Pais/bebê: A formação do apego. Porto Alegre, RS: Artes Médicas.

Klaus, M. H., Kennell, J. H., \& Klaus, P. H. (2000). Vínculo: Construindo as bases para um apego seguro e para a independência. Porto Alegre, RS: Artes Médicas Sul.

Lopes, R. de C. S., de Oliveira, D. S., Vivian, A. G., BohmgahrenI, L. M. C., Piccinini, C. A., \& Tudge, J. (2007). Sentimentos maternos frente ao desenvolvimento da criança aos 12 meses: Convivendo com as novas aquisições infantis. Psicologia: Teoria e Pesquisa, 23(1), 5-16. doi:10.1590/S0102-37722007000100002

Lopes, R. de C. S., Prochnow, L. P., \& Piccinini, C. A. (2010). A relação da mãe com suas figuras de apoio femininas e os sentimentos em relação à maternidade. Psicologia em Estudo, 15(2), 295-304.

Maldonado, M. T. (1997). Psicologia da gravidez. São Paulo, SP: Saraiva.

Marin, A. H., Donelli, T. M., Lopes, R. S., \& Piccinini, C. A. (2009). Expectativas e sentimentos de mães solteiras sobre a experiência do parto. Aletheia, 29, 57-72.

Marin, A. H., Gomes, A. G., Lopes, R. S., \& Piccinini, C. A. (2011). A constituição da maternidade em gestantes solteiras. Psico (Porto Alegre), 42(2), 246-254.

Oishi, K. L. (2014). O Jardim de Julia: A vivência de uma mãe durante o luto. Psicologia: Teoria e Pesquisa, 30(1), 5-11. doi:10.1590/S010237722014000100002
Penna, L. H., Carinhanha, J. L., \& Rodrigues, R. F. (2006). A mulher no pós-parto domiciliar: Uma investigação sobre essa vivência. Escola Anna Nery de Enfermagem, 10(3), 448-455. doi:10.1590/S1414-81452006000300013

Piccinini, C. A., Gomes, A. G., Moreira, L. E., \& Lopes, R. S. (2004). Expectativas e sentimentos da gestante em relação ao seu bebê. Psicologia: Teoria e Pesquisa, 20(3), 223-232. doi:10.1590/ S0102-37722004000300003

Piccinini, C. A., Gomes, A. G., Nardi, T., \& Lopes, R. S. (2008). Gestação e a constituição da maternidade. Psicologia em Estudo, 13(1), 63-72. doi:10.1590/S1413-73722008000100008

Rosa, R., Martins, F. E., Gasperi, B. L., Monticelli, M., Siebert, E. R., \& Martins, N. M. (2010). Mãe e filho: Os primeiros laços de aproximação. Escola Anna Nery Revista de Enfermagem, 14(1), 105-12. doi:10.1590/S141481452010000100016

Silva, F. B., Souza, L., \& Scorsolini-Comin, F. (2013). Significados da gravidez e da maternidade: Discursos de primíparas e multíparas. Psicologia: Teoria e Prática, 15(1), 19-34.

Soifer, R. (1980). Psicologia da gravidez, parto e puerpério. Porto Alegre, RS: Artes Médicas.

Spitz, R. A. (1998). O primeiro ano de vida. São Paulo, SP: Martins Fontes.

Stern, D. N. (1997). A constelação da maternidade: O panorama da psicoterapia pais/bebê. Porto Alegre, RS: Artes Médicas.

Strapasson, M. R., \& Nedel, M. N. B. (2010). Puerpério imediato: Desvendando o significado da maternidade. Revista Gaúcha de Enfermagem, 31(3), 521-528. doi:10.1590/S198314472010000300016

Szejer, M., \& Stewart, R. (1997). Nove meses na vida da mulher: Uma aproximação psicanalítica da gravidez e do nascimento. São Paulo, SP: Casa do Psicólogo.

Winnicott, D. W. (1999). Os bebês e suas mães. São Paulo, SP: Martins Fontes. (Original publicado em 1987)

Winnicott, D. W. (2000). Da Pediatria à Psicanálise: Obras escolhidas. Rio de Janeiro, RJ: Imago. (Original publicado em 1958)

Recebido: 16/05/2014

$1{ }^{a}$ revisão: 26/08/2014

$2^{a}$ revisão: $30 / 10 / 2014$

Aceite final: 07/11/2014 